\title{
An Eco-Friendly Approach for the Extraction of Antioxidant Components from Artemisia Annua Leaves Using Response Surface Methodology
}

\author{
Umer Younas ${ }^{1,2 *}$, Shahid Iqbal ${ }^{3 * *}$, Rashida Bashir ${ }^{4}$, Noreen Sajjad ${ }^{2}$, Zohaib Saeed ${ }^{5}$, \\ Muhammad Pervaiz ${ }^{2,5}$, Faiza Hassan², Faisal Ali², Saba Ibrahim5, Fozia Batool', \\ Ishtiaq Hussain'2, Munawar Iqbal ${ }^{1}$ \\ ${ }^{1}$ Department of Chemistry, University of Sargodha, Sargodha 40100, Pakistan \\ ${ }^{2}$ Department of Chemistry, The University of Lahore, Lahore, Pakistan \\ ${ }^{3}$ Department of Chemistry, University of Education Lahore, Jauharabad Campus, Pakistan \\ ${ }^{4}$ Division of Science and Technology, Faculty of Science, University of Education, Lahore, Pakistan \\ ${ }^{5}$ Department of Chemistry, Government College University Lahore, Lahore, Pakistan
}

Received: 21 August 2020

Accepted: 25 January 2021

\begin{abstract}
Drying methods, extraction techniques, solvents as well as extraction conditions affect the recovery of antioxidant components from botanical materials. In the current study, antioxidant compounds from leaf samples of $A$. апnиa were extracted using methanol as extraction solvent and orbital shaker assisted extraction technique and extraction technique was optimized using response surface methodology. Extraction conditions including rotation speed and extraction time were taken as independent variables and extraction was carried out for different time duration and at different rotation speed. A significant mutual effect of selected extraction conditions was recorded on the antioxidant potential of A. annua leaves and optimized conditions were determined employing response surface methodology. Statistical data revealed linear quadratic and interactive effect of extraction conditions on TPC, TFC and DDPH radical scavenging potential was significant because $p$-value is less than 0.05 . For the same antioxidant components, measured and predicted values were found to be close in agreement, indicating that the tested model is fit for the recovery of antioxidant components from A. annua leaves. Optimization of extraction conditions using response surface methodology may be helpful in making the extraction technique cost-effective and environment friendly.
\end{abstract}

Keywords: artemisia, antioxidants, extraction, optimization, RSM

\footnotetext{
*e-mail: umer0608analyst@gmail.com
}

** e-mail: ranashahid313@gmail.com 


\section{Introduction}

Artemisia annua is a herb of medicinal as well as industrial importance, as many bioactive compounds especially artemisinin, artemisinic acid, dihydroaritemisinic acid and arteannuin B have been reported from this plant [1], whereas Artemisinin is well proven antimalarial compound [2, 3]. A large number of Artemisia L. species are commonly found in Central Asia. Pakistan hosts 25 species and most of them are present in northern regions, i.e. ranges of Himalaya, Hindu Kush and Karakorum mountains in district Abbottabad, Chitral, Gilgit, Kashmir, Rawalpindi, Skardu and Swat. Local name of this plant is Afsantin or Afsantin jari and it is used for the treatment of malaria, cold, cough, fever and diarrhea $[4,5]$.

Artemisia annua is well known for its Antimicrobial, anti-inflammatory, antitumor and allelopathic properties [6]. Antioxidant potential of Artemisia annua leaves have also been studied by many researchers and recommended that this plant may be used as a source of natural antioxidants [7,8]. Antioxidants are the compounds that possess ability to scavenge free radicals, reactive oxygen $\left(\mathrm{O}_{2}{ }^{--}, \mathrm{HO}, \mathrm{H}_{2} \mathrm{O}_{2}\right)$ and nitrogen $\left(\mathrm{NO}^{*}, \mathrm{ONOO}^{-}\right)$species. These species cause oxidative damages to biomolecules such as DNA, protein and lipids, which results in the state of oxidative stress [9]. In addition to this, oxidative deterioration of lipid containing food has become one of the major problems in food industry. Therefore, use of antioxidants as food supplements for disease prevention in human body and as preservatives in food products has become mandatory nowadays [10]. Natural antioxidants from different parts (roots, shoots, leaves and fruits) of medicinal plants have received significant attention of researchers and consumers due to low cost, more efficient, less toxicological as compared to synthetic antioxidants [11, 12].

Yield, composition, purity and nature of extracted compounds are strongly influenced by the polarity of solvent, extraction method and extraction conditions [13, 14]. In our previously reported work, effect of different solvents on antioxidant potential of $A$. annua leaves has been studied and methanol was recommended as best solvent for extraction of antioxidant components from leaf matrix [15]. Among extraction methods, solid liquid extraction (SLE) techniques like maceration, percolation, soxhlet (reflux) extraction, sonication, and turbo-extraction (high speed mixing) are most commonly used due to lack of modern equipment [16]. However, some drawbacks such as use of huge amount of solvent and high extraction time have been highlighted for these techniques [17]. For orbital shaker assisted extraction method, parameters including extraction time and rotation per min (RPM) must be optimized, in order to make it cost effective and eco-friendly. Optimization of extraction process is achieved by employing different statistical tools such as response surface methodology (RSM) [18, 19]. RSM is exercised by the scientists to improve extraction efficiency of different methods with an aim to decrease extraction time, expenses, consumption of chemicals and to obtain maximum amount of target compounds [20, 21].

Therefore, the present work was undertaken to find out the effect of extraction conditions (rotation speed and extraction time) on antioxidant potential of A. annua leaves. The quality of extracts was evaluated in terms of total phenolic and total flavonoid contents and radical ( $\mathrm{DPPH}^{\circ}, \mathrm{ABTS}^{\cdot+}$ ) scavenging potential. On the basis of results, determination of optimum rotation speed and extraction time has been aimed to recover maximum amount of antioxidants from A. апnиa leaves, in lesser time and energy investment.

\section{Materials and Methods}

All the solvents, chemicals and reagents, used in this work, were of analytical grade. Folin-Ciocalteu (FC) reagent, Gallic acid, and Epicatechin was purchased from Merck (Darmstad, Germany). ABTS $^{\cdot+}$ and DPPH ${ }^{*}$ stable radicals were procured from Sigma Chemical Co. (St. Louis, MO, U.S.A.).

\section{Sample Collection and Preparation}

Samples of Artemisia annua L. leaves were collected from peripheral areas of Islamabad, Pakistan. Samples were initially washed with running tap water and then rinsed with distilled water. Hot air drying was carried out by placing samples in hot air oven and temperature was maintained at $40^{\circ} \mathrm{C}$ for two days. The dried samples were cooled in a desiccator at room temperature. Powder of dried leaves was prepared using grinder and were stored in sealed polyethylene bags at ambient conditions.

\section{Orbital Shaker-Assisted Extraction}

Powdered (50 $\mathrm{g}$ each) samples were added in $1 \mathrm{~L}$ extraction flask. In order to enhance the efficiency of extraction process, glass beads $(\sim 5 \mathrm{~g} /$ bead $)$ were added in the flask. A measured quantity $(500 \mathrm{~mL})$ of $70 \% \mathrm{MeOH}$ was added into the flask. After 5 minutes of addition of the solvent, samples were placed in adjustment position of orbital shaker. The warm air $\left(35^{\circ} \mathrm{C}\right)$ was allowed to pass through the shaker, while the rotation speed (X1) was kept at 50, 100 and $150 \mathrm{rpm}$ respectively. At each rotation speed, extracts were collected after specific time intervals (X2) 180, 360 and $540 \mathrm{~min}$. Extracted samples were filtered and centrifuged at 10,000 rpm for $15 \mathrm{~min}$. The extracts were concentrated using rotary evaporator. The collected extracts were kept in ambert colored glass bottles in a refrigerator (temperature $=+4^{\circ} \mathrm{C}$ ) [22]. The extracts were analyzed for TPC, TFC and \%age inhibition of radicals (DPPH' and $\left.\mathrm{ABTS}^{\cdot+}\right)$. 


\section{Optimization of Extraction Parameters}

Response surface methodology (RSM) was executed using well known software (Minitab 17) to find out the optimal conditions. A central composite design was employed to examine the effects of selected independent variables $\left(X_{1}=\right.$ Rotation speed and $X_{2}=$ Rotation time) on the dependent variables (TPC, TFC, and \% inhibition ( $\left.\mathrm{DPPH}^{*} \& \mathrm{ABTS}^{\circ+}\right)$ ). A two level full factorial design was employed examine the effect of extraction parameters and their interactions. The complete design, using methanol as extraction solvent, was based of 9 experimental points having one center point. Central Composite Design (CCD) was used to fit the data in a quadratic model. The regression equation model in uncoded units for each response is as follows:

$$
\mathrm{Y}=\beta_{0}-\beta_{1} \mathrm{X}_{1}-\beta_{2} \mathrm{X}_{2}+\beta_{11} \mathrm{X}^{2}+\beta_{1} \beta_{2} \mathrm{X}_{1} \mathrm{X}_{2}
$$

...where $\mathrm{Y}=$ response value, $\beta=$ constant coefficients, and $\mathrm{X}=$ independent variable.

Regression analysis $\left(\mathrm{R}^{2}\right)$ and ANOVA $(\mathrm{p}<0.05)$ was used to predict validity of model. Statistical implication of model and its parameters was evaluated at $5 \%$ probability level $(\alpha=0.05)$. At the end threedimensional response surface plots, of three level of a parameter having three different levels, were produced against one response variable (TPC, TFC, and ${ }^{*+} \%$ inhibition $\left(\mathrm{DPPH}^{*} \& \mathrm{ABTS}^{\cdot+}\right)$ ).

\section{Determination of Antioxidant Potential}

The extracts of $A$. апnиa leaves were analyzed for their content of total phenolic using spectrophotometric FC reagent assay [23] and results were expressed as $\mathrm{mg}$ gallic acid equivalent per gram of dried sample (mg GAE/g of dried sample). The determination of flavonoids was carried out by following an already reported spectrophotometric method [11] and TFC were calculated as $\mu \mathrm{g}$ Epicatechin equivalent/g of dried leaf samples ( $\mu \mathrm{g}$ EE/g of dried sample).

Free radical scavenging potential of $A$. annua leaves extracts was evaluated in terms of $\mathrm{DPPH}^{\circ}$ and $\mathrm{ABTS}^{++}$ scavenging potential. $\mathrm{DPPH}^{\cdot}$ assay was carried out by following a previously reported spectrophotometric method and scavenging potential was calculated as $\mathrm{DPPH}^{\circ}$ radical \% inhibition. Free racial scavenging potential of extracts was also determined employing ABTS radical cation scavenging assay using spectrophotometer. Results have been expressed as ABTS $^{+} \%$ inhibition $[24,25]$.

\section{Results and Discussion}

Central composite design was constructed and extractions were carried out for different time intervals and shaking speeds. Two selected parameters, such as rotation speed and extraction time were found influencing orbital shaking extraction process. Codes for independent variables and their corresponding values used in RSM analysis for orbital shaker assisted extraction (OSE) are such as X1 for speed (rpm) $50(-1)$, $100(0), 150(+1)$, and $\mathrm{X} 2$ for time (min) $180(-1), 360(0)$, $540(-1)$. The coded (independent variable), measured and predicted values (TPC, TFC and \%age inhibition $\left(\mathrm{DPPH}^{*}\right.$ and $\left.\mathrm{ABTS}^{-+}\right)$) are given in Table 2. Two level full factorial randomized regression equations are shown in Table 1 and the validation of the RSM was done using coefficients determination $\left(R^{2}\right)$ and $F$ and $P$ values. The $P$ value of any matter $<0.05$ with larger $F$ were considered significant [26].

\section{Recovery of Bioactive Compounds from A. апnиa Leaves}

Extracts of $A$. апnиa leaves, prepared by applying different set of extraction conditions, were analyzed for their antioxidant potential in terms of TPC and TFC. Significant variation in contents of total phenolics and flavonoids was recorded due to both selected independent variables.

\section{Total Phenolic Content (TPC)}

In orbital shaker-assisted extraction, extraction parameters (rotation speed and time) that can affect the recovery of TPC have been optimized in this work. Total phenolic content determined in A. аnnua extracts as function of rotation speed and time are graphically

Table 1. Polynomial equations and statistical parameters for $A$. annua leaves using orbital shaker-assisted extraction technique.

\begin{tabular}{|c|c|c|c|c|}
\hline $\begin{array}{c}\text { Response variables } \\
\text { A. annua }\end{array}$ & $2^{\text {nd }}$ order polynomial equation (Orbital shaker-assisted extraction) & $\mathrm{R}^{2}$ & $F$ & $P$ \\
\hline $\begin{array}{c}\text { TPC } \\
(\mathrm{mg} \mathrm{GAE} / \mathrm{g})\end{array}$ & $120.0+0.268 \mathrm{X}_{1}+0.1165 \mathrm{X}_{2}-0.00158 \mathrm{X}_{1}^{2}-0.000152 \mathrm{X}_{2}^{2}-0.000027 \mathrm{X}_{1} \mathrm{X}_{2}$ & 0.9849 & 1.95 & 0.039 \\
\hline $\begin{array}{c}\mathrm{TFC} \\
(\mu \mathrm{g} \mathrm{ECE} / \mathrm{g})\end{array}$ & $7.01-0.0084 \mathrm{X}_{1}+0.01031 \mathrm{X}_{2}+0.000005 \mathrm{X}_{1}^{2}-0.000017 \mathrm{X}_{2}^{2}+0.000009 \mathrm{X}_{1} \mathrm{X}_{2}$ & 0.9967 & 2.35 & 0.046 \\
\hline $\begin{array}{c}\text { DPPH } \\
\% \text { Inhibition }\end{array}$ & $67.00+0.1815 \mathrm{X}_{1}+0.0299 \mathrm{X}_{2}-0.000991 \mathrm{X}_{1}^{2}-0.000039 \mathrm{X}_{2}^{2}-0.000007 \mathrm{X}_{1} \mathrm{X}_{2}$ & 0.9714 & 2.51 & 0.039 \\
\hline $\begin{array}{c}\text { ABTS }+ \\
\% \text { Inhibition }\end{array}$ & $74.09-0.021 \mathrm{X}_{1}-0.0157 \mathrm{X}_{2}+0.000313 \mathrm{X}_{1}^{2}+0.000040 \mathrm{X}_{2}^{2}-0.000077 \mathrm{X}_{1} \mathrm{X}_{2}$ & 0.5575 & 0.75 & 0.635 \\
\hline
\end{tabular}


Table 2. Measured and predicted TPC, TFC and \% inhibition (DPPH $\left.\& \mathrm{ABTS}^{+}\right)$values for $A$. Annua leaves using orbital shaker-assisted extraction technique.

\begin{tabular}{|c|c|c|c|c|c|c|c|c|c|c|}
\hline & \multicolumn{2}{|c|}{$\begin{array}{c}\text { Independent } \\
\text { variables }\end{array}$} & \multicolumn{2}{c|}{$\begin{array}{c}\text { Response } \\
\text { (TPC, mg GAE/g) }\end{array}$} & \multicolumn{2}{c|}{$\begin{array}{c}\text { Response } \\
(\mathrm{TFC}, \mu \mathrm{g} \text { ECE/g) }\end{array}$} & \multicolumn{2}{c|}{$\begin{array}{c}\text { Response } \\
\text { (DPPH \% Inhibition) }\end{array}$} & \multicolumn{2}{c|}{$\begin{array}{c}\text { Response } \\
\text { (ABTS+ \% Inhibition) }\end{array}$} \\
\hline $\begin{array}{c}\text { Sr. } \\
\text { No. }\end{array}$ & $\mathrm{X}_{1}$ & $\mathrm{X}_{2}$ & Measured & Predicted & Measured & Predicted & Measured & Predicted & Measured & Predicted \\
\hline 1 & -1 & -1 & 147.09 & 145.59 & 7.29 & 7.37 & 75.58 & 76.14 & 70.56 & 71.57 \\
\hline 2 & -1 & 0 & 150.80 & 149.64 & 8.02 & 7.70 & 80.20 & 79.63 & 75.18 & 74.83 \\
\hline 3 & -1 & 1 & 143.49 & 145.27 & 7.93 & 7.90 & 79.30 & 79.18 & 74.28 & 73.30 \\
\hline 4 & 0 & -1 & 150.53 & 152.34 & 7.90 & 8.10 & 75.20 & 75.87 & 70.18 & 71.82 \\
\hline 5 & 0 & 0 & 148.79 & 147.32 & 7.80 & 8.00 & 78.16 & 78.17 & 73.14 & 74.34 \\
\hline 6 & 0 & 1 & 151.53 & 151.22 & 8.50 & 8.30 & 80.02 & 79.24 & 75.00 & 74.84 \\
\hline 7 & 1 & -1 & 142.07 & 141.20 & 7.35 & 7.27 & 77.54 & 77.65 & 72.52 & 71.91 \\
\hline 8 & 1 & 0 & 147.74 & 146.12 & 7.32 & 7.44 & 79.35 & 80.70 & 74.33 & 72.17 \\
\hline 9 & 1 & 1 & 145.85 & 148.20 & 7.85 & 8.08 & 78.50 & 77.27 & 73.48 & 74.05 \\
\hline
\end{tabular}

$\mathrm{X}_{1}=$ Coded units for speed, $\mathrm{X}_{2}=$ coded units for time

presented in three-dimensional surface plots (Fig 1). As rotation speed and extraction time increases, a corresponding increase in TPC was also recorded. However, data suggests that further high rotation speed for extraction or increase in time may not further enhance the recovery of phenolic compounds from
A. annua leaves. Therefore, increase in speed time will increase only cost of extraction without adding antioxidant components in extracts [27]. High TPC were produced at extraction time of 380 min, longer extractions at any rotation speed led to less recovery of antioxidants. Some previous studies have confirmed
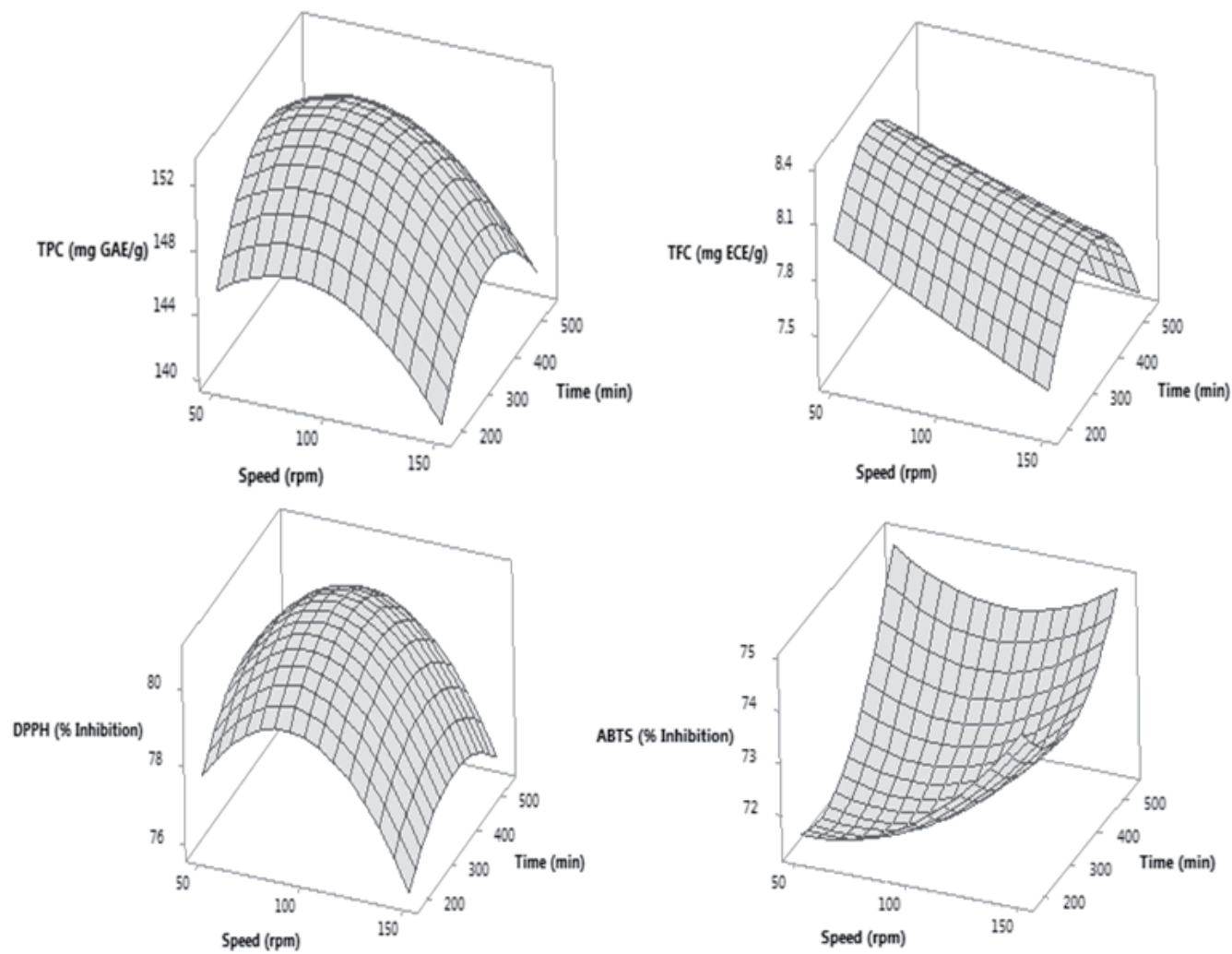

Fig. 1. Response Surface plots showing the effect of orbital shaker-assisted extraction parameters on TPC, TFC and \% inhibition (DPPH \& $\mathrm{ABTS}^{*+}$ ) of $70 \% \mathrm{MeOH}$ extracts of $A$. annua leaves. 
the degradation of extract components upon prolonged exposure of bioactives to extraction process [28]. Measured and predicted TPC values (RSM) are given in Table 2. Measured values for both response variables are in close agreement with the predicted values, indicating that model is satisfactory.

Statistical data (Table 1) revealed that the effect of speed and time under orbital shaker-assisted extraction treatment exhibited linear quadratic and interactive effect was significant because $\mathrm{p}$ value is less than 0.05 and results were significant for TPC recovery. $\mathrm{R}^{2}$ value for orbital shaker assisted extraction was 0.9849 exhibited that the method was best for the recovery. In many studies, excellent linear correlation between total phenolic content and antioxidant activity has been reported [29, 30]. Results of TPC in our study, confirmed that different parameters of extraction method can have significant influence on antioxidant activity of extracts.

\section{Total Flavonoid Content (TFC)}

Flavonoids are the largest subgroup of phenolic compounds that are well known for many biological activities such as antioxidant activity. These properties of flavonoids are generally attributed to their structural features. In the current study, increase in extraction time cause an increase in flavonoid content in extracts of $A$. annua leaves, but extraction to maximum time further decrease content of total flavonoid in prepared extract. Extracts prepared employing moderate rotation speed were found containing high amount of flavonoids. However, the mutual effect of selected extraction conditions was found to be almost same as discussed for TPC.

Responses for the recovery of TFC against different rotation speed and time were recorded (Fig. 1). Statistical data (Table 1) revealed that the effect of orbital shaking speed and time was significant as $p$ value is less than 0.05 , the linear quadratic and interactive effect of speed and time was also found significant. Measured and predicted TFC values (RSM) are given in Table 2. Predicted values for both response variables are in close agreement with the measured values, indicating a satisfactory model. $\mathrm{R}^{2}$ value exhibited that the method may be best fit for the recovery of TFC.

\section{Radical Scavenging Activities}

In order to determine radical scavenging activities of the extracts, two different methods i.e. $\mathrm{DPPH}^{-}$and $\mathrm{ABTS}^{-+}$scavenging assays were employed. $\mathrm{DPPH}^{\cdot}$ method is commonly used for the evaluation of antiradical potential of natural products including leaves. DPPH free radical (2,2-diphenyl-2picrylhydrazyl hydrate) gets converted to 1, 1,-diphenyl2-picryl hydrazine, when come in contact with hydrogen donating species, i.e. antioxidants [24]. This hydrogen donation ability of antioxidants leads towards formation of stable complex of free radicals, resulting in termination of lipid peroxidation [15]. Statistical data (Table 1) revealed that the effect of speed and time under orbital shaker assisted extraction treatment was significant because of $p$ value is less than 0.05 for linear quadratic and two way interactive effects for DPPH radical scavenging potential was noted. Predicted DPPH $\%$ inhibition values (Table 2 ) for both response variables are in close agreement with the measured values, indicating a satisfactory model. $\mathrm{R}^{2}$ value (Table 1) for microwave extraction was 0.9714 that method is fit for the recovery of DPPH radical scavenging agents and three dimensional plots have presented in Fig. 1.

The working mechanism of the $\mathrm{ABTS}^{\cdot+}$ method for the evaluation of antioxidant activity is the same as that of the $\mathrm{DPPH}^{*}$ method, but the $\mathrm{ABTS}^{\cdot+}$ method is more reliable than the $\mathrm{DPPH}^{\bullet}$ method, due to solubility of the $\mathrm{ABTS}^{-+}$reagent in both aqueous and organic solvents and rapid reaction with lipophilic as well as hydrophilic antioxidant species as compared to $\mathrm{DPPH}^{\circ}$ [24].

Statistical data (Table 1) revealed that the mutual effect of speed and time under orbital shaker-assisted extraction treatment was insignificant because of $p$ value is greater than 0.05 for linear quadratic and two way interactive effects for $\mathrm{ABTS}^{\cdot+}$. However, predicted ABTS $^{+} \%$ inhibition values (RSM) are given in Table 2 for both response variables are in close agreement with the measured values, indicating a satisfactory model.

\section{Optimization}

Optimization of extraction process for antioxidant components from different medicinal plant leaves with different polyphenolic composition depends upon case investigation. No universal model available that can describe the optimal conditions for the best recovery of bioactive ingredients from botanical material. For the extraction of different group of bioactive compounds from A. Annua leaves requires different set of conditions and extracts enriched in particular components can be prepared with greater ease.

RSM was employed to find out the optimized conditions (Table 3) for the maximum recovery of antioxidant components. The equations developed for A. annua leave extracts were significant up to $95 \%$ confidence level. It was observed that with the change of extraction time and rotation speed (180 $\mathrm{min}$ to 540 min and 50 to 150 RPM) significantly influence the yields of bioactives from A. Annua if we consider the parameters TPC, TFC and DPPH radical scavenging activity. A notable increase in the recovery of phenolic and flavonoids compounds was observed, when extraction is carried out from 180 to $360 \mathrm{~min}$. This set of examinations highlighted for the first time that the $A$. annua leaves bioactive compounds can be better recovered if leaves are extracted with orbital shaking extraction method using set of calculated optimized conditions. 
Table 3. Optimized conditions to recover maximum antioxidant components from A. Annua leaves.

\begin{tabular}{|c|c|c|}
\hline Antioxidant activity & $\begin{array}{c}\text { Time } \\
(\mathrm{min})\end{array}$ & $\begin{array}{c}\text { Speed } \\
(\mathrm{rpm})\end{array}$ \\
\hline $\mathrm{TPC}(\mathrm{mg}$ GAE$/ \mathrm{g})=152.884$ & 380.082 & 82.1644 \\
\hline $\mathrm{TFC}(\mu \mathrm{g}$ ECE $/ \mathrm{g})=8.32437$ & 315.306 & 50.3182 \\
\hline $\mathrm{DPPH}^{*} \%$ inhibition $=80.7985$ & 382.645 & 89.5933 \\
\hline $\mathrm{ABTS}^{+} \%=74.7705$ & 537.810 & 148.942 \\
\hline
\end{tabular}

\section{Conclusions}

In the current study, orbital shaker assisted extraction of antioxidant components from A. аппиа leaves was successfully optimized. Extracts of $A$. апnиа leaves, prepared under different extraction conditions of shaking speed and time, were found containing different amount of antioxidant compounds i.e. phenolics and flavonoids and antiradical compounds. A significant difference in recovery of antioxidant compounds and DPPH radical scavenging agents was observed due to variation in extraction conditions that confirms the effect of extraction conditions on recovery of antioxidant components from botanical material. Furthermore, in case of orbital shaker assisted extraction of antioxidant components from $A$. аппиа leaves, extractions conditions have been optimized using RSM for the maximum recovery of target compounds. Prior development of functional foods and nutraceuticals, the authors suggest the use of statistical tools to optimize the extraction process that may be helpful in securing maximum befits associated with botanical materials.

\section{Conflicts of Interest}

The authors declare no conflict of interest.

\section{References}

1. BRISIBE E.A., UMOREN U.E., BRISIBE F., MAGALHÄES P.M., FERREIRA J.F, LUTHRIA D., WU X., PRIOR R.L. Nutritional characterisation and antioxidant capacity of different tissues of Artemisia аппиа L. Food Chem. 115 (4), 1240, 2009.

2. JUTEAU F., MASOTTI V., BESSIERE J.M., DHERBOMEZ M., VIANO J. Antibacterial and antioxidant activities of Artemisia апnиa essential oil. Fitoterapia. 73, 532, 2002.

3. FERREIRA J.F., LUTHRIA D.L. Drying affects artemisinin, dihydroartemisinic acid, artemisinic acid, and the antioxidant capacity of Artemisia annua L. leaves. J. Agric. Food Chem. 58 (3), 1691, 2010.

4. HAYAT M.Q., KHAN M.A., ASHRAF M., JABEEN S. Ethnobotany of the genus Artemisia L. (Asteraceae) in Pakistan. Ethnobo. Re. App. 7, 147, 2009.
5. MANNAN A., AHMED I., ARSHAD W., ASIM M.F., QURESHI R.A., HUSSAIN I., MIRZA B. Survey of artemisinin production by diverse Artemisia species in northern Pakistan. Malaria J. 9, 310, 2010.

6. KIM W.S., CHOI W.J., LEE S., KIM W.J., LEE D.C., SOHN U.D., SHIN H.S., KIM W. Anti-inflammatory, Antioxidant and Antimicrobial Effects of Artemisinin Extracts from Artemisia annua L. Korean J. Physio. Pharmacol. 19 (1), 21, 2015.

7. WAN X., NIU Y., ZHENG X., HUANG Q., SU W., ZHANG J., ZHANG L., WANG T. Antioxidant capacities of Artemisia annua L. leaves and enzymatically treated Artemisia annua L. in vitro and in broilers. Anim. Feed Sci. Tech. 221, 27, 2016.

8. SKOWYRA M., GALLEGO M., SEGOVIA F., ALMAJANO M. Antioxidant properties of Artemisia annua extracts in model food emulsions. Antioxidants. 3 (1), 116, 2014.

9. GRAMZA A., PAWLAK-LEMANSKA K., KORCZAK J., WASOWICZ E., RUDZINSKA M. Tea extracts as free radical scavengers. Pol. J. Environ. Stud. 14 (6), 861, 2005.

10. WOOTTON-BEARD P.C., MORAN A., RYAN L. Stability of the total antioxidant capacity and total polyphenol content of 23 commercially available vegetable juices before and after in vitro digestion measured by FRAP, DPPH, ABTS and Folin-Ciocalteu methods. Food Res. Int. 44 (1), $217,2011$.

11. METOUI M., ESSID A., BOUZOUMITA A., FERCHICHI A. Chemical composition, antioxidant and antibacterial activity of tunisian date palm seed. Pol. J. Environ. Stud. 28 (1), 2019.

12. MUNIR A., SULTANA B., BASHIR A., GHAFFAR A., MUNIR B., SHAR G.A., NAZIR A., IQBAL M. Evaluation of antioxidant potential of vegetables waste. Pol. J. Environ. Stud. 27 (2), 2018.

13. CHENG V.J., BEKHIT AE-DA., MCCONNELL M., MROS S., ZHAO J. Effect of extraction solvent, waste fraction and grape variety on the antimicrobial and antioxidant activities of extracts from wine residue from cool climate. Food Chem. 134 (1), 474, 2012.

14. BOULEKBACHE-MAKHLOUF L., MEDOUNI L., MEDOUNI-ADRAR S., ARKOUB L., MADANI K. Effect of solvents extraction on phenolic content and antioxidant activity of the byproduct of eggplant. Ind. Crop. Prod. 49, 668, 2013.

15. IQBAL S., YOUNAS U., CHAN K.W., ZIA-UL-HAQ M., ISMAIL M. Chemical composition of Artemisia annua L. leaves and antioxidant potential of extracts as a function of extraction solvents. Molecules. 17 (5), 6020, 2012.

16. YUSNAWAN E. Effects of different extraction methods on total phenolic content and antioxidant activity in soybean cultivars. In: IOP Conference Series: Earth and Environmental Science. IOP Publishing, 2018.

17. BOUDHRIOUA $\mathrm{N}$ : Comparison of the efficiency of different extraction methods on antioxidants of maltease orange peel. Int. J. Food Nutr. Sci., 3, 2016.

18. YI Y., LU W., HONG D., LIU H., ZHANG L. Application of Dual-Response Surface Methodology and Radial Basis Function Artificial Neural Network on Surrogate Model of the Groundwater Flow Numerical Simulation. Pol. J. Environ. Stud. 26 (4), 2017.

19. URIBE E., DELGADILLO A., GIOVAGNOLI-VICUÑA C., QUISPE-FUENTES I., ZURA-BRAVO L. Extraction techniques for bioactive compounds and antioxidant capacity determination of chilean papaya (Vasconcellea pubescens) Fruit. J. Chem. 2015. 
20. VARNALIS A., BRENNAN J., MACDOUGALL D., GILMOUR S. Optimisation of high temperature puffing of potato cubes using response surface methodology. J. Food Eng. 61, 153 (2), 2004.

21. YANG X-L., XIA M-Q., CHEN M., SHEN D-Q., FU D-F., SONG H-L. Optimization of solid-phase extraction for pretreatment of selected estrogens in sewage by response surface methodology. Pol. J. Environ. Stud. 23 (6), 2014.

22. KSHIRSAGAR P., GAIKWAD N., PAI S., BAPAT V. Optimization of extraction techniques and quantification of swertiamarin and mangiferin by using RP-UFLC method from eleven Swertia species. S. Afr. J. Bot., 108,81, 2017.

23. KHAN A.S., ARIF K., MUNIR B., KIRAN S., JALAL F., QURESHI N., HASSAN S.M., SOOMRO G.A., NAZIR A., GHAFFAR A. Estimating total phenolics in taraxacum officinale (1.) extracts. Pol. J. Environ. Stud. 28 (1), 497, 2019.

24. IQBAL S., YOUNAS U., CHAN K.W., SARFRAZ R.A., UDDIN M. Proximate composition and antioxidant potential of leaves from three varieties of Mulberry (Morus sp.): a comparative study. Int. J. Mol. Sci. 13 (6), 6651, 2012.

25. BAGUES M., HAFSI C., YAHIA Y., SOULI I., BOUSSORA F., NAGAZ K. Modulation of photosynthesis, phenolic contents, antioxidant activities, and grain yield of two barley accessions grown under deficit irrigation with saline water in an arid area of tunisia. Pol. J. Environ. Stud. 28 (5), 2019.

26. IQBAL M., IQBAL N., BHATTI I.A., AHMAD N., ZAHID M. Response surface methodology application in optimization of cadmium adsorption by shoe waste: a good option of waste mitigation by waste. Ecol. Eng. 88, 265, 2016.

27. TAN M., TAN C., KHOO H., HO C. Optimization for extraction on total phenolic content and radical scavenging capacity of Henna (Lawsonia inermis) stems using response surface methodology. Int. Food Res. J. 21 (2), 789, 2014.

28. SOUZA M.M., SILVA B.D., COSTA C.S., BADIALEFURLONG E. Free phenolic compounds extraction from Brazilian halophytes, soybean and rice bran by ultrasoundassisted and orbital shaker methods. An. Acad. Bras. Cienc. 90 (4), 3363, 2018.

29. ANWAR F., ALI M., HUSSAIN A.I., SHAHID M. Antioxidant and antimicrobial activities of essential oil and extracts of fennel (Foeniculum vulgare Mill.) seeds from Pakistan. Flavour Frag. J. 24, 170, 2009.

30. IQBAL S., BHANGER M., ANWAR F. Antioxidant properties and components of bran extracts from selected wheat varieties commercially available in Pakistan. LWTFood Sci. Tech. 40 (2), 361, 2007. 